\title{
Development and introduction of a module on medical humanities for MBBS Interns: a pedagogical experiment
}

\author{
Gill M.K. ${ }^{1}$, Mannan R. ${ }^{2}$, Uppal N. ${ }^{3}$, Kukreja S. ${ }^{4}$, Verma N. ${ }^{5}$, Kaur J. ${ }^{6}$ \\ ${ }^{1}$ Dr. Manmeet Kaur Gill, ${ }^{2}$ Dr. Rahul Mannan, ${ }^{3}$ Dr. Neha Uppal, ${ }^{4}$ Dr. Sahiba Kukreja; all authors attached with Sri Guru \\ Ram Das Institute of Medical Sciences and Research, Amritsar, ${ }^{5}$ Dr. Niket Verma, Assistant Professor, Department of \\ Internal Medicine Army Medical College, Delhi, ${ }^{6}$ Dr. Jasmine Kaur, Reader, Oro-Facial and Maxillofacial Surgery, Sri \\ Guru Ram Das Institute of Dental Sciences and Research
}

Corresponding Author: Dr. Jasmine Kaur, Reader, Oro-Facial and Maxillofacial Surgery, Sri Guru Ram Das Institute of Dental Sciences and Research, Amritsar, Punjab, India. E-mail: rahulmannan@gmail.com

\begin{abstract}
Introduction: Loss of "empathy/ compassion" and "humanism" in undergraduate students and doctors is leading to poor patient care. The present medical curriculum has emphasis on following standardized medical "checklists" which is skewed towards treating "disease" and not "illness" (holistic approach towards both body and soul). This has led to increased patient doctor conflicts and poor patient care, which is increasingly being blamed on "burn out" for both physicians and medical students. Aim and Objectives: To develop a well-structured and validated module on medical humanities for MBBS interns and do a pilot run of the same on a group of volunteer interns to assess their knowledge and their perception regarding the same. Materials and Methods: The project was carried out at Sri Guru Ram Das Institute of Medical Sciences and Research, Amritsar, comprising of 27 MBBS interns. Need assessment was done by three rounds of Delphi culminating in developing a validated and structured module on humanities. The pilot of the module was run. Pre and Post assessments were conducted. A Feedback was also taken from the students as well as the faculty in the form of questionnaire and Focused group discussion. Results: Overall there was an increase in knowledge about medical humanities and the module was well appreciated and received by the interns, core faculty and MEU observers. No one was dissatisfied by the module. Further suggestions recommended were to increase the duration of the module by 2-3 days, making it mandatory for MBBS and rest of the clinical staff of the hospital (faculty, residents and nurses) and inclusion of a forensic expert as a part of core faculty. Conclusion: The study resulted in formation of a structured and validated module on humanities.
\end{abstract}

Keywords: Doctor-patient relationship, Humanities, Module, Pilot Study, Undergraduate

\section{Introduction}

According to the latest guidelines by MCI; the purpose of undergraduate education is to prepare a competent physician. The present medical curriculum is packed with cold scientific "facts" with emphasis on standardized medical "checklists" (history taking/ diagnosis/ management), which is skewed towards treating "disease" and not "illness" (holistic approach towards both body and soul).

Since medical students spend most of their time in memorizing and processing information, the lack of encouragement and time for reflection endangers the adoption of a dogmatic approach to medical practice $[1,2]$.

Manuscript received: $29^{\text {th }}$ July 2019

Reviewed: $9^{\text {th }}$ August 2019

Author Corrected: $14^{\text {th }}$ August 2019

Accepted for Publication: $19^{\text {st }}$ August 2019
Popularity and adoption of evidence based medicine (EBM) although successful in integrating evidence and the ideal professional practice of medicine by applying analytical approach of data collection has led to students spending their talent and efforts in finding just one correct answer, failing to reflect on deeper questions regarding their role in as health care providers [3].

All this has led to loss of "empathy/ compassion" and "humanism" in undergraduate students and doctors is leading to poor patient care. This type of present medical education has led to increased patient doctor conflicts and poor patient care, which is increasingly being blamed on "burn out" (emotional exhaustion, depersonalization and low sense of accomplishment) in $60 \%$ physicians and $50 \%$ third year medical students [4]

Research states that "compassion" and empathy" can be induced and students can be trained to be interested to the 


\section{Original Research Article}

patient as a whole, rather than to the symptom alone. Humanities share with medicine the focus on humans. Medical humanities provide insight into human conditions, illness and suffering, perception of oneself, as well as into professionalism and responsibilities to self and others, colleagues and patients. Introduction into the world of arts and literature induces the development of observational skills, analytical reasoning, empathy and self-reflection [5].
This study was conducted to assess perception of present interns, faculty and old passed out students of a tertiary care teaching hospital of north India towards humanities in medicine and also to design a well-structured and validated module on medical humanities for MBBS interns.

An additional purpose was to train the selected faculty to conduct the developed module and to do a pilot run on a small sample of current interns.

\section{Methods}

Ethical approval: This study was carried out after obtaining ethical approval from the institutional ethics committee.

Settings: The project was designed and undertaken in Sri Guru Ram Das Institute of Medical Sciences and Research, Amritsar, tertiary care teaching hospital in North India.

Study design: It was a qualitative study

The project was undertaken at a tertiary care teaching hospital in North India catering to both rural and urban population with an annual intake of 150 undergraduates MBBS students. After taking permission from the ethics committee of the college and Dean Academics a core committee of 4 faculty members was made with 4 additional members of medical educational unit (MEU) chosen as observers for the module demonstration. For the pilot run 27 volunteer interns (chosen randomly from the whole batch) were recruited. Detailed methodology is described below and also illustrated as Figure1.

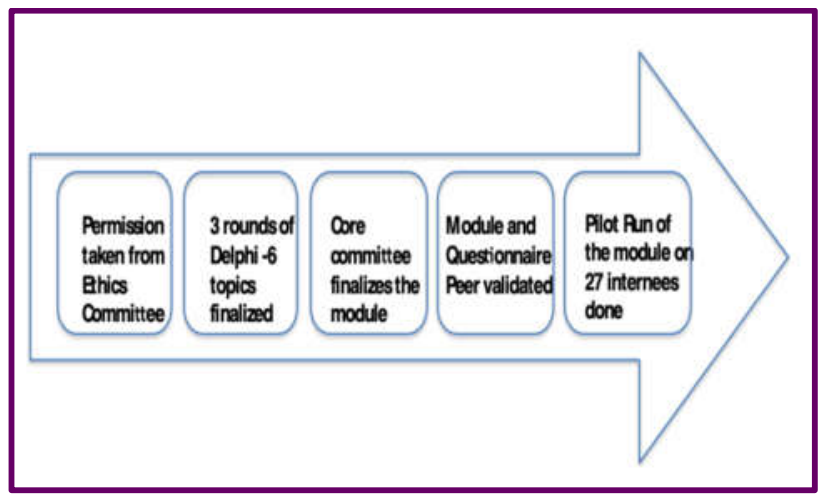

Figure-1: Flow chart of standardization and validation of the module on humanities.

Need assessment by Delphi method: Delphi method (which is a structured communication technique) was planned incorporating old alumni, present interns, few current and past faculty members of the institute, MEU members of both our and other institutes and subject experts to do a need assessment regarding the current knowledge about medical humanities and its importance in medical scenario.

Two rounds of Delphi were conducted over Google Forms in form of questionnaires containing both open and close ending questions over a period of 15-20 days to arrive upon a consensus regarding topics relevant to humanities in medical sciences and tools (media) to teach them. A list of Topics important for doctor-patient relationship and tools according to highest priority to the lowest was made for incorporation in the final module.

Development of the module: A core committee (comprising of interested MEU members of the institute, one invited faculty member each from departments of medicine, surgery, orthopedics, pediatrics and otorhinolaryngology and few representative interns and post graduate students) was constituted. The committee met and designed sessions on the basis of the finalized topics and tools relevant to medical humanities as arrived by consensus through the 2 rounds of Delphi method. 


\section{Original Research Article}

A final round of Delphi was conducted with developed module with sessions incorporated for validation by both peer and external experts.

Development of feedback questionnaire: Pre and post-tests regarding the knowledge of medical humanities and feedback questionnaire were constructed and was peer validated. The developed questionnaire was also tested for reliability for which Cronbach's alpha was employed with a value of 0.768 on standardized items. The consent and the anonymity of the questionnaire were stated in the body of the questionnaire.

Selection of faculty, sensitization and post module feedback: Three more faculty members (comprising of MEU and nonMEU members) were chosen on the basis of the positive feedback/ interest shown in the topic. The first session with the faculty members was the sensitization session wherein the faculty was introduced to the concept of Empathy and Compassion in relation to doctor patient relationship and the proposed student intervention i.e. Module on Medical Humanities through video presentation and pictures. A second session with the faculty members was held to apprise them of the results of student's post-test performance, assessment and the feedback. Feedback by the faculty was taken by means of one to one in-depth interview and as responses to the questionnaire. Four MEU members observed the module administration and gave their feedback as one to one in-depth interview and as responses to the questionnaire.

Discussion with students, sensitization and post module feedback: Brief interaction was held with the students in the MEU room about current scenario of lack of empathy/ compassion and lack of communication with the patients. A pre-test on concepts and knowledge regarding medical humanities was administered. Following this, the students were introduced to various elements of patient care through the module on medical humanities by using various tools. A post-test was administered, and feedback was taken by means of peer-validated semi-structured questionnaire as described above. A week afterwards a focus group discussion (FGD) was also conducted on 6 participants.

Module on humanities: The project was carried out on 27 MBBS interns divided into 4 Sub-groups for activities such as think-pair share and larger group activities. The run time of all the modules was designed as that of 60 minutes.

- The Session-1 was on body language and posture and importance of it as a tool for communicating in various settings such as an OPD and indoor/ Casualty and ER.

- The Session-2 was on doctor-patient relationship and its types. A video-clip of a movie was shown and reading material given and students were asked to present the various aspects in 4 groups in the form of posters.

- The Session-3 was on patient suffering in the form of narratives (Poetry) with Physician playing the role of a witness.

- The Session-4 was on art of history taking where finer points were explained on communication, body language and posture and listening by means of role-play.

- The Session-5 was on breaking bad results and breaking death, which was taken up as video-clip demonstration, Narration and Role-play.

- The Session-6 was on bioethics and ethical dilemma vis-à-vis humanism, which was taken up as case studies and a movie clip.

Collection of student and faculty feedback: A Feedback was taken from the students and faculty in the form of questionnaire to record their experiences, perception and attitude towards the Module on Humanities. Focus group discussions (FGDs) were done with the students and faculty after taking the feedback to gather their opinions regarding their experiences and feedback towards the module know their opinions about the conduct and their overall perception of the module. Statistics employed: Analysis was done using students' T-test, descriptive statistics and qualitative methods (narrative analysis).

\section{Results}

The results of the study are as under:

a) Delphi technique for need assessment:

Round-1: $100 \%$ of the respondents felt there was need to introduce the concept of medical humanities in the undergraduate teaching as there was a sense of "burnout" due to current practice of medical education leading to poor patient care.

The consensus was developed on the following topics important for humanities module: 
- Patient Narration / Patient Suffering

Original Research Article

- Doctor Patient Relationship

- Breaking Bad News and Death

- Bioethics

The tools/media shortlisted were:

- Paintings

- Photographs

- Poetry

- Narration

- Role Plays

- Movie Clips/ Videos

Round-2: The topics shortlisted were asked to grade by the participants as must include, should include and can include in the round 2. The following topics were rated as the most priority to the least to be included in the module as:

1. Communicating bad results in a compassionate and empathetic way $[16 / 16 ; 100 \%]$

2. Medical ethics $[14 / 16 ; 87.5 \%]$

3. Patient suffering $[13 / 16 ; 81.25 \%]$

4. Professional etiquettes $[11 / 16 ; 68.75 \%]$ and patient narration $[11 / 16 ; 68.75 \%]$

5. Patient body language and posture $[10 / 16 ; 62.5 \%]$

Round-3: Based upon these finalized topics, a module along with hand-outs was developed and peer validated. case scenarios and role-plays were finalized and faculty guide for every session was prepared (Table 1).

After pilot run, based upon feedback of interns', topic of classical paintings in humanities was removed from the module and other changes in the teaching-learning methodology and case scenarios were made and a standardized, validated 6 hours teaching module for interns in medical humanities in patient care was developed.

Table-1: Faculty guide for a session on doctor-patient relationship

\begin{tabular}{|l|c|c|l|}
\hline Activity & Time & Faculty & \multicolumn{1}{c|}{ Resources } \\
\hline Video clip: Doctor-patient relationship & $10 \mathrm{~min}$. & RM & Movie clip of "Patch Admas" \\
\hline $\begin{array}{l}\text { Discussion on the video clip } \\
\text { Participants enlist: } \\
\text { - Good points elicited } \\
\text { - Wrong points elicited }\end{array}$ & $10 \mathrm{~min}$. & $\begin{array}{c}\text { RKG \& } \\
\text { on flip chart }\end{array}$ & Flip charts, Marker pens \\
\hline $\begin{array}{l}\text { Distribution of reading material } \\
\text { - Introduction to doctor patient relationship } \\
\text { - Importance of doctor patient relationship }\end{array}$ & $05 \mathrm{~min}$. & MKG & $\begin{array}{l}\text { Photocopies of reading } \\
\text { material }\end{array}$ \\
\hline $\begin{array}{l}\text { Poster presentation in } 4 \text { sub-groups } \\
\text { - Different aspects of doctor } \\
\text { patient relationship }\end{array}$ & $25 \mathrm{~min}$ & $\mathrm{SK}$ & $\begin{array}{l}\text { Charts, marker pens, tapes, old } \\
\text { magazines, adhesive, scissors }\end{array}$ \\
\hline \begin{tabular}{l} 
Debriefing \\
\hline
\end{tabular} & $10 \mathrm{~min}$. & $\mathrm{RM}$ & -- \\
\hline
\end{tabular}

Overall close to $78 \%$ participants agreed that the module has able to incorporate the themes chosen in the round 2 according to priority assigned and close to $22 \%$ somewhat agreed upon the same. No participant disagreed upon the incorporation of themes in the final module. 


\section{Original Research Article}

b) Pre-post-test evaluation: 27 interns who participated in the module were given pre and post-tests of 10 MCQs of total marks randomly given as 5 . Their pre and post-test were coded. Mean score for pre-test was $2.75 \pm 0.22$ and for post-test was $4.38 \pm 0.06$, with an improvement of $78.03 \%$ which was statistically significant (Figure-2).

The scores reflected an overall improvement in the learning, awareness and evaluation of the interns about humanities especially concepts of empathy and compassion in patient care.

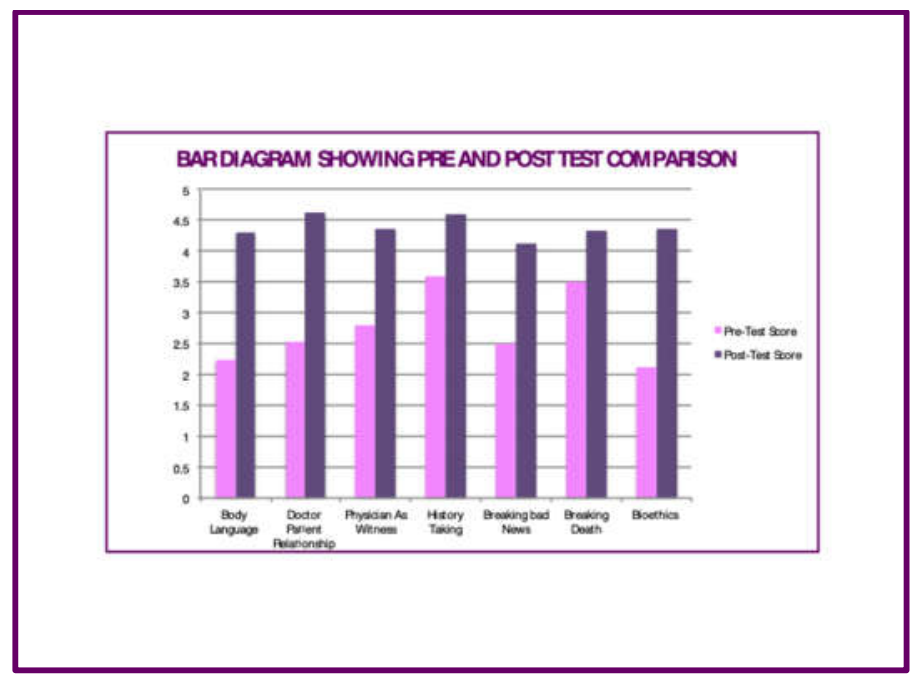

Figure-2: Comparative histogram of pre and post-test evaluation

c) Results of the feedback forms- Students: Students' feedback was collected after the workshops on every session on two counts first on criteria of teaching quality and interactivity and second the quality of tools used and reading material provided, on a five point Likert scale of $1=$ Poor, $2=$ Average, $3=$ Satisfactory, $4=$ Good, $5=$ Excellent.

Similarly, perceptions of interns about the overall module were collected on five-point Likert scale of very satisfied $=5$ to very dissatisfied $=1$. For last two items, reverse rating scale was used.

The responses to questions directed at individual sessions are summarized in Table 2 and 3. As is reflected in tables 2-4 and Figure-3 and 4, majority of interns were satisfied with the overall module as well as individual sessions.

No intern was dis-satisfied or rated poor the quality of reading material, teaching quality and overall module training.

Table-2: Responses of interns in rating individual sessions on basis of teaching quality and interactivity on a 5- point Likert scale.

\begin{tabular}{|c|c|c|c|c|c|}
\hline Sessions & $\begin{array}{c}\text { Excellent } \\
(\%)\end{array}$ & $\begin{array}{c}\text { Good } \\
(\%)\end{array}$ & $\begin{array}{c}\text { Satisfactory } \\
(\%)\end{array}$ & $\begin{array}{c}\text { Average } \\
(\%)\end{array}$ & $\begin{array}{r}\text { Poor } \\
(\%)\end{array}$ \\
\hline $\begin{array}{l}\text { Body language and body postures in } \\
\text { communication }\end{array}$ & 59 & 33 & 7 & 0 & 0 \\
\hline Doctor patient relationship & 19 & 15 & 11 & 7 & 4 \\
\hline Physician as witness & 56 & 22 & 22 & 0 & 0 \\
\hline History taking & 19 & 15 & 11 & 7 & 4 \\
\hline Breaking bad results/news & 44 & 48 & 7 & 0 & 0 \\
\hline Breaking death & 19 & 15 & 11 & 7 & 4 \\
\hline Bioethics & 56 & 37 & 7 & 0 & 0 \\
\hline
\end{tabular}

Rating scale: $1=$ Poor, $2=$ Average, $3=$ Satisfactory, $4=$ Good, $5=$ Excellent 
Original Research Article

Table-3: Responses of interns in rating individual sessions on basis of tools (media) used and reading material provided on a 5-point Likert scale.

\begin{tabular}{|l|c|c|c|c|c|}
\hline \multicolumn{1}{|c|}{ Sessions } & $\begin{array}{c}\text { Excellent } \\
(\mathbf{\%})\end{array}$ & $\begin{array}{c}\text { Good } \\
\mathbf{( \% )}\end{array}$ & $\begin{array}{c}\text { Satisfactory } \\
\mathbf{( \% )}\end{array}$ & $\begin{array}{c}\text { Average } \\
\mathbf{( \% )}\end{array}$ & $\begin{array}{c}\text { Poor } \\
\mathbf{( \% )}\end{array}$ \\
\hline $\begin{array}{l}\text { Body language and body postures in } \\
\text { communication }\end{array}$ & 26 & 56 & 15 & 4 & 0 \\
\hline Doctor patient relationship & 33 & 44 & 22 & 4 & 0 \\
\hline Physician as witness & 26 & 56 & 19 & 4 & 0 \\
\hline History taking & 26 & 52 & 22 & 4 & 0 \\
\hline Breaking bad results/news & 30 & 44 & 26 & 4 & 0 \\
\hline Breaking death & 30 & 56 & 15 & 4 & 0 \\
\hline Bioethics & 52 & 37 & 11 & 4 & 0 \\
\hline
\end{tabular}

Rating scale: 1 = Poor, 2 = Average, 3 = Satisfactory, $4=$ Good, $5=$ Excellent

Table-4: Perceptions of interns about overall module on medical humanities.

\begin{tabular}{|c|c|c|c|c|c|c|c|}
\hline $\begin{array}{c}\text { Feedback } \\
\text { parameters }\end{array}$ & Total & $\begin{array}{c}\text { Very } \\
\text { satisfied } \\
(\%)\end{array}$ & $\begin{array}{c}\text { Satisfied } \\
(\%)\end{array}$ & $\begin{array}{c}\text { No } \\
\text { opinion } \\
(\%)\end{array}$ & $\begin{array}{c}\text { Dissatisfied } \\
(\%)\end{array}$ & $\begin{array}{c}\text { Very } \\
\text { dissatisfied } \\
(\%)\end{array}$ & Total \\
\hline $\begin{array}{l}\text { Module notes and } \\
\text { reading material }\end{array}$ & 27 & 26 & 67 & 7 & 0 & 0 & 100 \\
\hline $\begin{array}{l}\text { Interactivity of } \\
\text { lectures }\end{array}$ & 27 & 74 & 26 & 0 & 0 & 0 & 100 \\
\hline $\begin{array}{l}\text { Videos, role plays, } \\
\text { narrations: quality }\end{array}$ & 27 & 70 & 30 & 0 & 0 & 0 & 100 \\
\hline Overall opinion & 27 & 41 & 59 & 0 & 0 & 0 & 100 \\
\hline
\end{tabular}

Rating scale: $1=$ Very dissatisfied, 2 = dissatisfied, $3=$ neither satisfied nor dissatisfied, $4=$ satisfied, $5=$ very satisfied

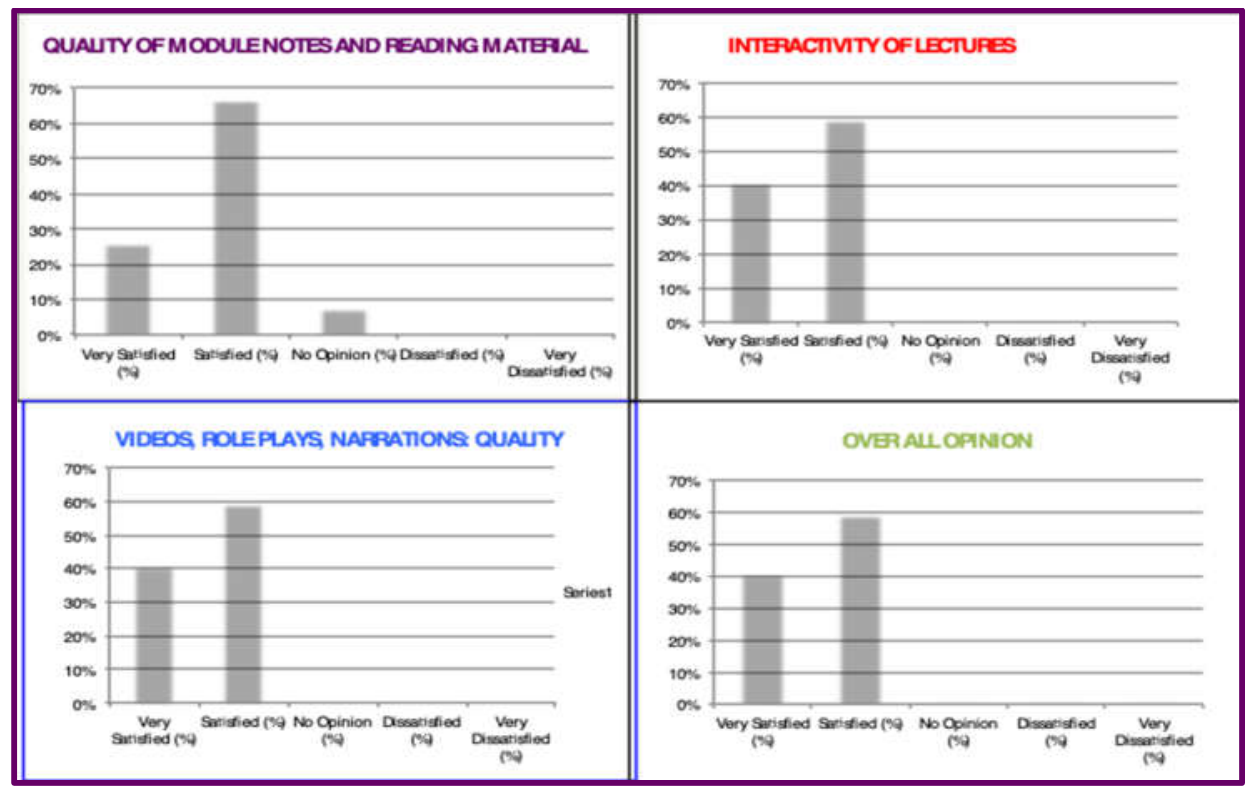

Figure-3: Comparative Histograms depicting perceptions of interns about overall module. 


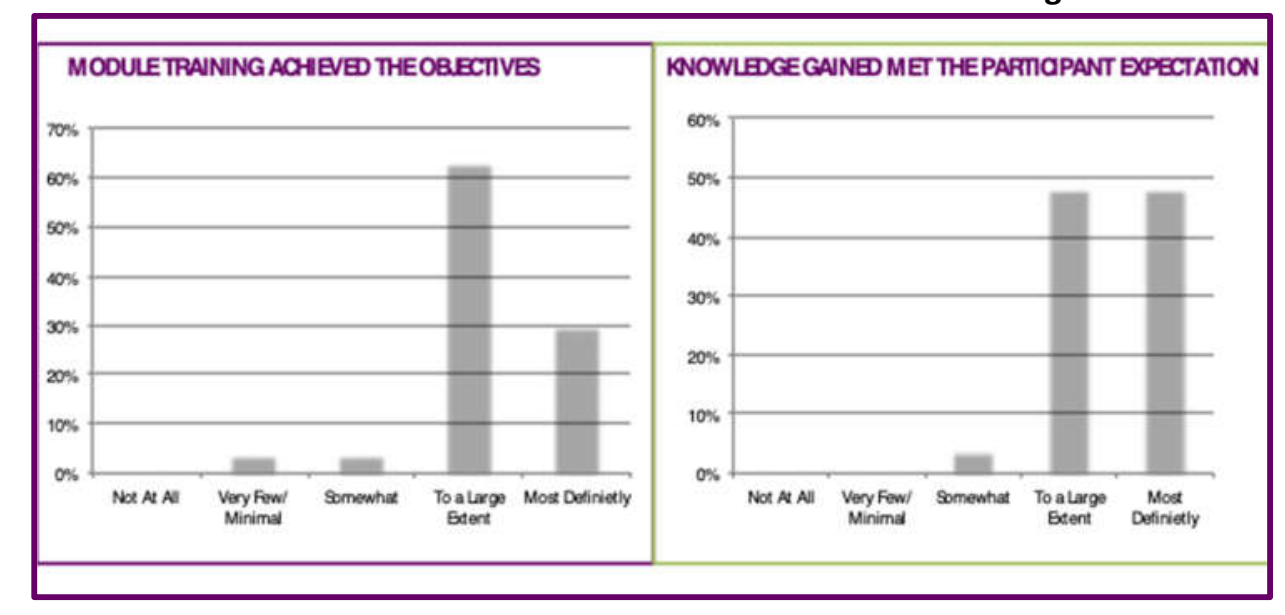

Figure-4: Comparative Histogram showing perception about module on reverse rating scale

The following are some of the responses to the open-ended question in the interns' feedback questionnaire that asked them to specify - a. How will you apply the knowledge gained from this module in your clinical practice? $\mathrm{b}$.

List any two good things about this module, c. Give any suggestions to improve the module. No negative feedback was received in all 27 responses, which were duly and properly filled.

How will you apply the knowledge gained from this module in your clinical practice? Copied verbatim:

- The art of listening and communication are the best things to practice in our profession.

- Being more attentive and empathetic to my patients.

- I will spend more time on personal interaction with my patients rather than relying on clinical reports.

- It helped me realize that I have to establish a rapport with my patients.

- I will spend more time on history taking as $80 \%$ diseases can be diagnosed on history.

- The session on patient suffering via poetry made me very emotional.

- I will be interacting and spending more time with my patients

- It made me think about so many aspects “out of medical textbook" I never thought about before.

List any two good things about this module: Copied verbatim:

- Informative/productive/interesting/amazing/positive

- Sessions were interactive

- It opens your "Eyes" and forces you to think about becoming a better doctor

- Exact and concise but comprehensive

- Group activities were conducted

- Use of role plays/ case scenarios/video Clips for teaching and discussion

- It was a new learning experience especially the one about breaking bad news and death

- Group discussions were very helpful to view everyone's thoughts.

- Session on "body language" and "body postures"

- Improved knowledge on bioethics.

- The Speakers and free meal (loved the samosa $\odot)$ )/ The teachers and their knowledge regarding topics.

- Everything was awesome/wonderful experience/ very enlightening

- Freedom to speak and communicate freely

- The content

- Overall, it was an amazing session, really interactive and definitely stimulated our "Sensory cotices". Thank You $\odot$.

Pathology Update: Tropical Journal of Pathology \& Microbiology Available online at: www.medresearch.in 613 | P a g e 


\section{Original Research Article}

Give suggestions to improve the module: Copied verbatim:

- It should have more time devoted to it 2-3 days and use more videos.

- Include a forensic expert

- These workshops should be held more often and throughout the year and mandatory in MBBS

- Module should be delivered to college teachers and nursing staff also.

- More breaks in between/more time should be devoted to individual sessions

- Reading material given should be made more pictorial and colorful.

- Please include session on medical laws in bioethics session because as internees lack knowledge about the concerned issue.

Hence the above responses showed that the module was found refreshing and had high satisfaction rate and encouraged active student participation, discussions and gave clearer and in-depth understanding of the topic.

Students were in favour that the module on humanities was helpful in improving the understanding of better doctor patient relationship and also increased the feeling of empathy and compassion towards patients. Following are some of the collages made by the sub-groups during the workshop highlighting doctor-patient relationship. (Figure 5)
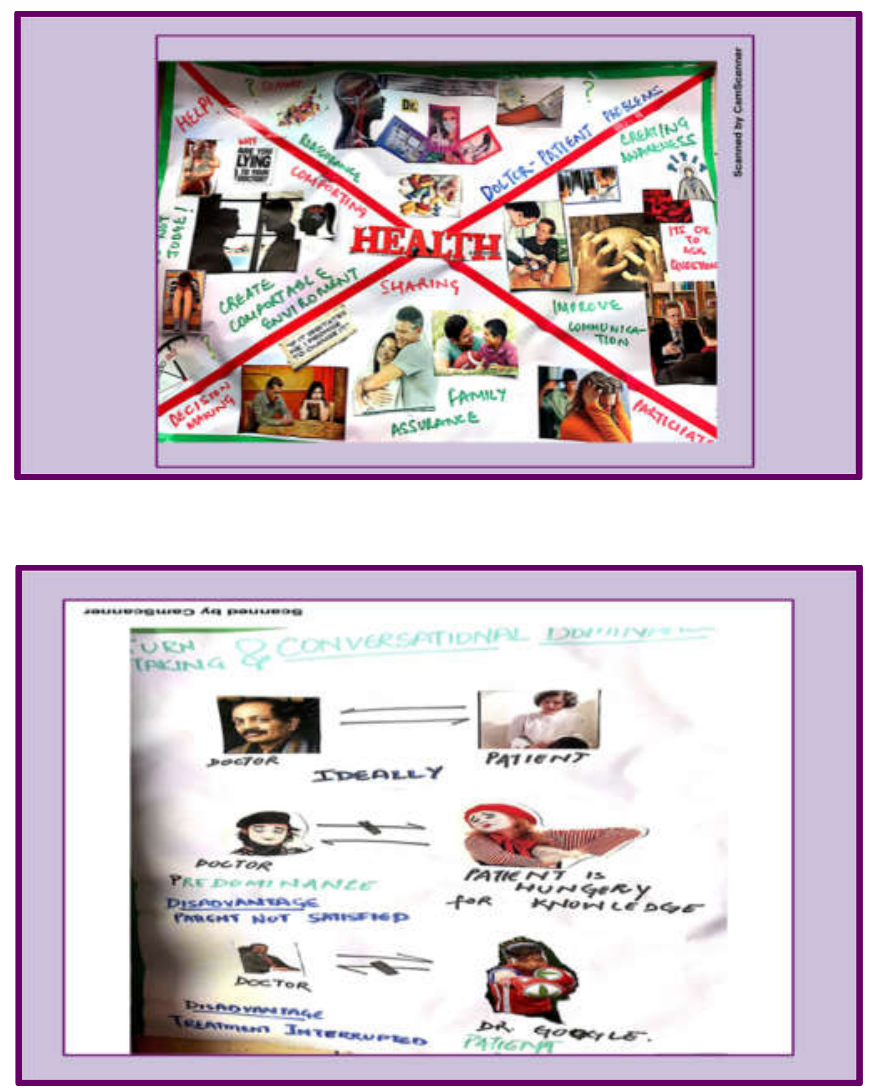

Figure-5a and b Collages made by Interns on various aspects of doctor patient relationship.

d) Coding of the raw data from intern focused group discussions and faculty in-depth interviews

Code: Module need assessment (both students and faculty perceptions): $\mathrm{N}$

Disconnect between theory/practical/patient care: N1

To improve doctor-patient encounters: N2

Part of MBBS curriculum: N3 
Code: Intern attitude and perceptions on pilot run of module: S

Original Research Article

Emotional: Experienced empathy and compassion: S1

Interactive and Motivational: S2

"Listening" to patients/ patients' sufferings: S3

Compulsory for all: S4

Increase Time and Days of module: S5

Code: Behavior and perceptions of faculty on pilot run of module: $\mathrm{F}$

Improved knowledge regarding humanities: F1

Enthusiastic and full participation by students: F2

Compulsory for all students: F3

Innovative and Interactive Sessions: F4

More Time and Days needed for Module: F5

Code: Outcome: E

More sensitive to patient needs: $\mathrm{O} 1$

Better Doctors: $\mathrm{O} 2$

Better Practice: $\mathrm{O} 3$

e) Themes generated from the analyses of the transcript

Intern focus group discussion:

- Majority was of the opinion that medical humanities should be included in all phases of MBBS.

- Majority agreed that patient is suffering, and doctors are not "listening" anymore.

- Found the module very helpful, interesting, interactive and motivating to increase a better doctor-patient relationship.

- Got "emotional" at more than one instance throughout the period of module.

- The modules made us feel more empathetic and compassionate towards the patient's suffering.

- Should be made compulsory for all the doctors, residents and nurses

- Please follow throughout the year.

- Spread it over 2-3 days and devote more time.

\section{* Core faculty in-depth interview:}

- Module delivery has improved the core faculties' own knowledge in medical humanities

- All interns and first year postgraduates should be made to take this module as a part of induction

- Module should be delivered to clinical faculty also

- If possible, the concepts of medical humanities should be started from the first year itself and should be taken through whole MBBS course with few credit hours to be devoted for the same in every year.

\section{* MEU observers in-depth interview were:}

- Module delivery was conducted in a very innovative and interactive way and sensitized them to the concept of medical humanities

- The concept is burning need of the hour and should be included in MBBS curriculum starting from MBBS first year.

- The module designing and delivery was very compliant, and the participants were quite receptive.

- Has touched very essential and pertinent themes and has been dealt in a very sensitive manner

- Participants could have been facilitated to give more organized role plays

- Module should be increased in duration to 2 or more days with more time given to individual sessions. 


\section{Original Research Article}

f) Narrative analyses: The thematic analyses of the intern FGD shows that the interns felt that there was an existing disconnect between patient care and the knowledge and skills acquired over 5 years of rigorous studies. The current teaching is too much leaned towards scientific knowledge and clinical reports and there is very little actual "time "given to patients needs and sufferings with very less "listening" and making "rapport" with the patients. Almost all the participants agreed that the concepts of communication, body language, breaking bad news and bioethics are necessary and should be part of the learning curriculum of the undergraduate studies. The participants also were unanimous that such modules should be made mandatory for the rest of the health care working staff including senior consultants and even nursing staff. Another suggestion was to follow it throughout the yea devoting a few periods or hours in a vertical integrated way. Both the interns and the faculty wanted the module to be spread over 2-3 days with more time devoted to each session and for debriefing and self-reflection. The module was appreciated by both the core faculty as well as MEU observers and found it refreshing and innovative. It was suggested that more facilitated role plays, and forensic expert be included to teach the medical laws in the bioethics session as a core faculty.

\section{Discussion}

Students should be trained to be interested to the patient as a whole, rather than to the symptom alone; to be interested in people rather than in diseases. Introduction into the world of arts and literature induces the development of observational skills, analytical reasoning, empathy and self-reflection [5].

Clinical judgment is largely visually based and in art observation is "seeing" [6,7]. It is a general phrase commonly used that the doctor "sees" patients, without actually realizing the meaning of this phrase. In order to become a competent physician, it is important that the future doctor is able to "see' rather than just "look"; therefore, students should be trained to deep seeing. Medicine and art are inter-related, already from the Renaissance time, with artists working closely with anatomists and surgeons [8].

Literature is the source of information about the nature and source of human emotions and behavior and of narratives of illness, and increases imagination and empathy $[9,10]$. Images of disease and death are common in literature and can serve as important recourses for medical education, since they increase the awareness of conditions and experiences one may not have [11]. Narrative methods are widely applied in medicine. Patients tell their stories to their doctors, who tell stories to their colleagues when presenting cases and face the patient as a text that needs interpretation [12, 13].

Besides patients' narratives of illness, there are themes of illness and images of physicians in well-known novels as well as a wealth of literature written by physicianwriters, such as Francois Rabelais, John Keats, Sir A Conan Doyle, Anton Chekhov, A.J. Cronin and Walker Percy [5]. The comprehension of medical ethics and professional deontology guides the patient-doctor relationship, as well as the relations between physicians and their colleagues. In India many of the aspects of Medical Humanities are covered by "Medical
Ethics" and such courses, which are included in the curriculum of many Medical Schools such as St. John's Medical College Bengaluru since 1988, and has been adopted by its affiliating university - Rajiv Gandhi University of Health Sciences in the form of 40 hours program throughout MBBS training. In other institutes, particularly Adesh Institute of Medical Sciences Bathinda and SGRD Medical college Amritsar sporadic efforts have been made to develop and implement ethical teaching on experimental basis but have still not part of curricula. In neighbouring country, Pakistan, too efforts are underway to design such modules $[14,15,16]$.

The proposal is to incorporate humanities-based teaching material into the undergraduate curriculum of Indian medical schools. UCMS has an active Medical humanities unit with a specialty journal of the same being published in-house, which is widely circulated. The Medical Humanities course is already integrated in the curriculum of many medical schools of Europe, USA and Australia, usually for one semester in the first years and includes presentations and essays by small groups on the above-mentioned entities [5]. The outcome of the present propose that the humanities course will encompass the use of literature (written by physicians, patients or narrating illness) and arts (visual, in the form of painting or photographic exhibits, and art critic lectures and performing). Independent humanities research projects, e.g. in sociology, anthropology, history etc can also be included [17].

\section{Limitations}

- Time management was a big limitation as the concept was too vast to be completed in one day.

- Another major limitation felt was the need of a forensic expert to address the session of bioethics pertaining to medical laws and a Clinical faculty to address to some issues of role modelling and behavioral ethics in clinical settings. 


\section{Conclusion}

Curriculum innovation in the form of development of a structured and validated module on humanities was seen as a very positive and interesting way to teach a hitherto a new concept. The module in its pilot run was able to evoke laughter, tears, empathy, emotions, arguments and love for humanity. The end result take home message in the form of coding which was written in almost every feedback form was "Listening", "Communication", "My Patients", "I will spend more time" and "I will make a rapport".

What this study adds to the existing knowledge?

In this study a standardized and validated module has been prepared after doing a need-assessment of topics from alumni, present internees, medical faculty (past and present) and outside subject experts through Delphi and assessing institutional needs. The pilot of the module has been successfully delivered to a batch of 27 volunteer interns with training (cum sensitization) of three more faculty members.

This study clearly interprets that interns and faculty are receptive about the concept of medical humanities and the participants develop imagination and abilities for interpretation of data through analytical and synthetical reasoning, skills of close observation and careful interpretation of the patient "language', empathy for the patients and conceptualize and construct personal and professional values. The module would add richness to medical education and practice and support the development of an exceptional medicine that constantly progresses and satisfies the communities' social, ethical and scientific needs.

\section{Author's contribution}

Dr. Manmeet Kaur Gill, Dr. Rahul Mannan and Dr. Sahiba Kukreja: Conceptualized the study and are the senior authors on the manuscript who conducted the pilot workshop on humanities.

Dr. Neha Uppal: Was one of the resource persons for the pilot workshop and took a session in module.

Dr. Niket Verma: Helped with evaluation of data, narrative analysis and statistics

Dr. Jasmine Kaur: Complied findings and helped with manuscript construction, writing and proof reading and involved in submission of final project report

Acknowledgement: This project was a part of fulfilling requirements for Advanced Course of Medical Education (ACME)- 2017. Authors would like to acknowledge the guidance and help provided by Dr. Tejinder Singh (Director, CMCL-FRI) and Dr. Dinesh
Badyal (Co-Director, CMCL-FRI) for constant motivation and guidance throughout this study. Authors also acknowledge the help rendered by Dr. Rajiv Mahajan ( Head and Prof, AIMSR, Bathinda), Dr Anjali Jain ( Head, Department of Anatomy, CMC, Ludhiana), Gita Sharma (Ex- Director Principal, SGRDIMSAR, Amritsar), A P Singh (Dean Colleges, SGRDIMSAR), Dr. Richa Ghay, Dr. Sukhjinder, Dr. Monica Lalit Piplani, Dr. Kanika (MEU members, SGRDIMSAR, Amritsar) and Dr. Amandeep Kaur ( Associate Professor, Biochemistry Dept, SGRDIMSAR, Amritsar). A special thanks to Dr. Gurupriya Anand (Resident, Pathology Department, SGRDIMSAR, Amritsar) for her suggestions and critical review to help refine the module.

Findings: Nil; Conflict of Interest: None initiated Permission from IRB: Yes

\section{References}

1. Lewis BE. Narrative medicine and healthcare reform. J Med Humanit. 2011;32(1):9-20.doi: 10.1007/s10912010-9123-3.

2. Gordon J. Medical humanities: to cure sometimes, to relieve often, to comfort always. Med J Aust. 2005;182 (1):5-8. doi:https://doi.org/10.5694 /j.1326- 5377. 2005. tb06543.x

3. Hood K, Jacobson L, Houston H. Medicine and selfimage in literature. Lancet. 2002;359(9310):981. doi:10. 1016/S0140-6736(02)08008-X

4. Charon R. Narrative and medicine. N Engl J Med. 2004;350(9):862-864.doi:10.1056/NEJMp 038249

5. Batistatou A, Doulis EA, Tiniakos D, Anogiannaki A, Charalabopoulos K. The introduction of medical humanities in the undergraduate curriculum of Greek medical schools: challenge and necessity. Hippokratia. 2010;14 (4):241-243.

6. Bleakley A, Farrow R, Gould D, Marshall R. Making sense of clinical reasoning: judgement and the evidence of the senses. Med Educ. 2003;37(6):544-552. doi: https://doi.org/10.1046/j.1365-2923.2003.01542.x

7. Crawford JM. Evidence-based interpretation of liver biopsies. Lab Invest. 2006;86(4):326-334. doi:10.1038/ labinvest.3700403

8. Boisaubin EV, Winkler MG. Seeing patients and life contexts: the visual arts in medical education. Am J Med Sci. 2000;319(5):292-296. doi:10.1097/00000441200005000-00005 
9. Oyebode F, Pourgourides C. Literature and medicine. Lancet. 1996;348(9031):894. doi:10.1016/S0140-6736 (05) 64766-6

10. Batistatou A, Charalabopoulos K. The picture of Oscar X. Nature. 2008; 455(7214):834. doi: 10.1038/ 455834a.

11. Bolton G. Literature and medicine. Lancet. 2001; 357(9266): 1441-1442. doi:10.1016/S0140-6736 (00) 04583-9

12. McLellan MF. Literature and medicine: physicianwriters. Lancet. 1997;349(9051):564-567. doi:10.1016/ S0140- 6736(97)80120-1

13.McLellan MF, Jones AH. Why literature and medicine? Lancet. 1996; 348 (9020): 109-11. doi:10. 1016 / s0140-6736(96)03521-0
14. Mahajan R, Goyal PK, Sidhu TK, Kaur U, Kaur S, Gupta V. Module for Interns in Medical Ethics: A Developmental Diegesis. Int J Appl Basic Med Res. 2017;7 (Suppl 1):S52-S56. doi: 10.4103/ ijabmr. IJABMR_170_17.

15. Rameshkumar K. Ethics in medical curriculum; Ethics by the teachers for students and society. Indian J Urol. 2009; 25(3):337-339. doi: 10.4103/ 0970-1591. 56192.

16. Ahsin S, Shahid A, Gondal GM. Teaching communication skills and medical ethics to undergraduate medical student.JAdvan Med Edu Prof.2013;1(3):72-76

17. Shapiro J, Rucker L. Can poetry make better doctors? Teaching the humanities and arts to medical students and residents at the University of California, Irvine, College of Medicine. Acad Med. 2003;78 (10): 953-957.

\section{How to cite this article?}

Gill M.K., Mannan R., Uppal N., Kukreja S., Verma N, Kaur J. Development and introduction of a module on medical humanities for MBBS Interns: a pedagogical experiment. Trop J Path Micro 2019;5(9):607-618.doi:10.17511/jopm. 2019.109.01. 